\title{
Left ventricular external subannular plication: An indirect off-pump mitral annuloplasty method in a canine model
}

\author{
András Kollár, MD, PhD, FRCSC \\ Violetta Kékesi, PhD \\ Pál Soós, MD \\ Alexander Juhász-Nagy, MD, DSci
}

See related editorial on page 942.
From the Cardiovascular Research Lab, Postdoctoral $(\mathrm{PhD})$ School, Semmelweis University, Budapest, Hungary.

Received for publication Dec 24, 2002; revisions requested Feb 5, 2003; revisions received Feb 15, 2003; accepted for publication March 17, 2003.

Address for reprints: András Kollár, MD, $\mathrm{PhD}$, Cardiovascular Research Lab, Semmelweis University, Varosmajor 68, Budapest, 1122 Hungary (E-mail: andraskollar@hotmail.com).

J Thorac Cardiovasc Surg 2003;126:977-82

Copyright () 2003 by The American Association for Thoracic Surgery

$0022-5223 / 2003 \$ 30.00+0$

doi:10.1016/S0022-5223(03)00588-9
Objective: Mitral annular dilatation in cardiomyopathy is due to left ventricular chamber enlargement. We hypothesized that the size of the mitral annulus could be "indirectly" reduced if the plicating sutures were placed externally into subannular myocardium.

Methods: In healthy mongrel dogs, an off-pump technique to create external subannular plication was designed and implemented. The sutures were placed directly into the myocardium below the atrioventricular groove. In 14 dogs, the sutures were tightened with tourniquets, and after a 30-minute observation period the hearts were arrested. Subsequently the mitral annular size was measured with the tourniquets still tight and then released. In 6 dogs, circumflex coronary blood flow, coronary blood flow reserve, and left ventricular systolic function were also measured during experiments.

Results: Subannular plication had no significant effect on the animals' hemodynamic stability, and it did not generate any arrhythmias. Suture tightening effectively reduced postmortem mitral annular diameter and circumference by $17 \%$ (30.8 $\pm 0.4 \mathrm{~mm}$ and $96.8 \pm 1.1 \mathrm{~mm}$ vs $25.6 \pm 0.4 \mathrm{~mm}$ and $80.4 \pm 1.1 \mathrm{~mm}$, respectively, $P<.001)$ and mitral annular area by $31 \%\left(747 \pm 17 \mathrm{~mm}^{2}\right.$ vs $517 \pm 14 \mathrm{~mm}^{2}, P<$ $.001)$. Circumflex coronary blood flow $(39.0 \pm 7.9 \mathrm{~mL} / \mathrm{min}$ vs $37.2 \pm 7.2 \mathrm{~mL} / \mathrm{min}$, $P$ not significant) and left ventricular systolic function $\left(\mathrm{dP} / \mathrm{dt}_{\max } 1705 \pm 237 \mathrm{~mm}\right.$ $\mathrm{Hg} / \mathrm{s}$ vs $1928 \pm 330 \mathrm{~mm} \mathrm{Hg} / \mathrm{s}, P$ not significant) remained unchanged $(\mathrm{n}=6)$.

Conclusion: In healthy hearts, subannular ventricular plication resulted in a significant indirect mitral annular size reduction without compromising circumflex coronary blood flow or left ventricular systolic performance.

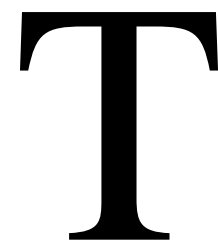

he mitral annulus, an integral part of the left atrioventricular valve apparatus, is a dynamic structure. ${ }^{1,2}$ During diastole it assumes a more circular shape and also becomes larger, facilitating ventricular filling, whereas in systole, as a result of ventricular contraction, it becomes smaller and more oval in shape, contributing to valve competence. $^{2}$ Annular dilatation is a secondary pathologic process seen in many forms of valve disease and in cases of cardiomegaly. With the exception of rheumatic disease, when extensive fibrosis or calcification may prevent large changes in the actual annular size, ${ }^{3}$ mitral annular dilatation is associated with left ventricular (LV) dilatation irrespective of the primary etiology. ${ }^{4-7}$

The clinical significance of annular dilatation has been long recognized in mitral valve repair surgery. ${ }^{8}$ There have been many different annular "remodeling" techniques described in the literature, ${ }^{9-19}$ but the concept of shortening mainly posterior or mural annular size is essentially the same in all. ${ }^{8}$ Irrespective of the method used, annuloreduction with complete ${ }^{9,10}$ or incomplete ${ }^{11,12}$ rings, with suture alone, ${ }^{13-15}$ with pericardium, ${ }^{16}$ or with some other foreign material ${ }^{11,17}$ always targets the 


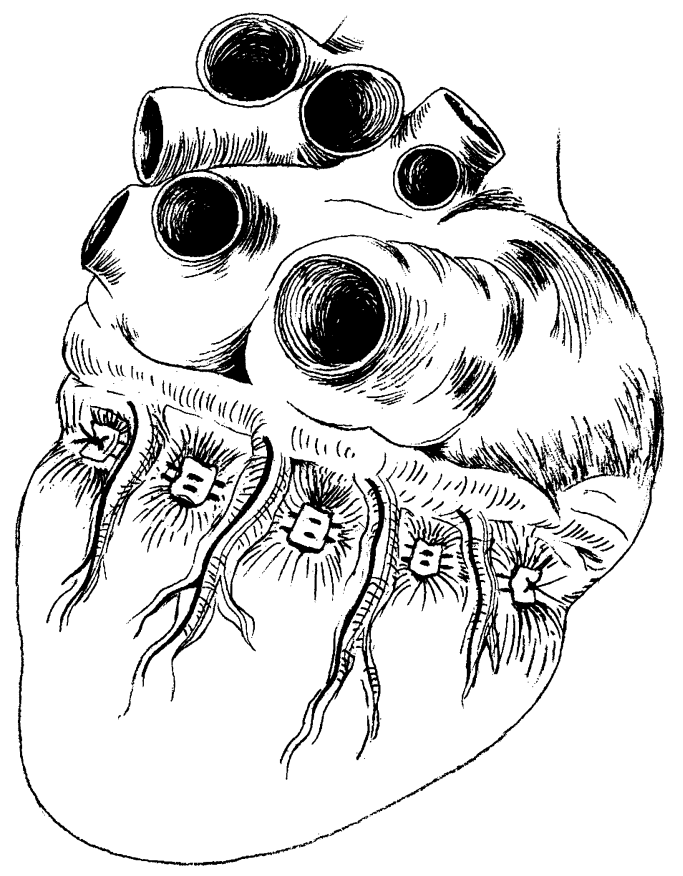

Figure 1. Artistic illustration of external subannular myocardial plication procedure, posterior view of LV. In experiments, rubber tourniquets were used on both ends of sutures (see description in text).

posterior part of the mitral annulus, corresponding to $\mathrm{LV}$ free wall with the mural leaflet attached to it. ${ }^{1}$ This segment of the annulus has no well-defined fibrotic ring, ${ }^{1}$ and therefore it is less resistant to dilatational forces affecting primarily the underlying LV myocardium. ${ }^{4-7}$ In various forms of cardiomyopathy, although annular enlargement by itself cannot be blamed for the developing mitral regurgitation, dilatation of the annulus pulls the leaflets further apart, contributing to valve incompetence. ${ }^{4-6}$ This hypothesis is also supported by the fact that the so-called downsizing annuloplasty, developed by Bolling ${ }^{18}$ most recently, has been successfully used to eliminate mitral regurgitation in patients with cardiomyopathy.

At present, however, all available annuloplasty methods are open procedures that require cardiopulmonary bypass support. At the Semmelweis University, we have developed an off bypass external plication method, and under experimental conditions we have successfully reduced mitral annular size without opening the left atrium (LA).

\section{Material and Methods}

In this study healthy, adult mongrel dogs weighing 16 to $25 \mathrm{~kg}$ were used. In 14 animals, the feasibility of the newly designed procedure was assessed. Detailed hemodynamic studies were done in 6 of these dogs. The experiments were conducted in accordance with the Guide for Care and Use of Laboratory Animals prepared by the Institute of Laboratory Animal Resources, National Research Council, and published by the National Academy Press, revised 1996. Appropriate government regulations endorsed in our country were also followed.

\section{Surgical Preparation}

Dogs were anesthetized with intravenous pentobarbital sodium (Nembutal $30 \mathrm{mg} / \mathrm{kg}$ ), intubated and ventilated (Cape ventilator; Cape Eng Co, Warwick, England) throughout the experiment. Volume replacement (physiologic saline [Salsol A] and dextran 40 [Rheomacrodex]) was given by peripheral venous line, and the animal's femoral artery was cannulated and connected to a physiologic pressure transducer (Spectramed P 23 XL; Spectramed, Oxnard, Calif) for continuous blood pressure monitoring. Transsternal thoracotomy was done through the fifth intercostal space, and the heart was suspended in the pericardial cradle.

To insert the external subannular sutures, the apex of the heart was elevated with the help of a wet gauze sponge acting like a sling. This way the LV free wall came into full view, and the coronary artery anatomy on this surface could be carefully inspected. After 5 to 10 minutes of hemodynamic stabilization, a double row of 3-0 Prolene (Ethicon, Inc, Somerville, NJ) running suture was inserted parallel with the atrioventricular groove. The placement of the sutures was subepicardial, starting on the right side of the posterior descending artery, diving deep underneath all coronary artery branches, and ending anteriorly just left to left anterior descending coronary artery. The most anterior parts of the sutures were placed with the sling removed and the heart allowed back in the cradle. During suture placement, particular care was taken to avoid injury to any arterial or venous coronary branches. Each entry and exit point on the surface was pledget supported to prevent the suture material from cutting into the myocardium (Figure 1). The completed suture line encircled LV free wall, with the exception of the anterior interventricular groove with the left anterior descending coronary artery in it. Red rubber tourniquets were then placed on both ends of the sutures, and a trial plication was done with repeated inspections of the posterior surface of the heart.

We had no reliable means to measure in vivo how much plication was "safe." Overzealous tightening of the suture line creates visible discoloration (ischemia) on the inferior LV wall within 1 to 2 minutes. However, during preliminary studies we observed that with gentle and gradual tightening a well-distinguished myocardial "plication" (Figure 1) could be created on the subannular region without any signs of ischemia or compression of the subepicardial coronary arteries. The tightening maneuver we describe is empirical; we therefore decided to support our observations with coronary blood flow studies.

\section{Data Acquisition}

After suture placement, the animal's hemodynamic condition was allowed to stabilize without any manipulations for 15 to $20 \mathrm{~min}$ utes. The tourniquets were then tightened as previously noted, and a 30-minute observation period with continuous electrocardiographic and blood pressure monitoring followed. Before the animal was killed, the apex of the heart was elevated again to inspect the LV free wall and the plicating suture line to make sure that no 
ischemia had occurred. The heart was then arrested in diastole and was excised in toto from the chest with the tourniquets still tight.

\section{Postmortem Dissection and Data Collection}

The LA above the atrioventricular groove was trimmed off to expose the mitral orifice, which was measured with Carbomedics valve sizers (Sulzer Carbomedics Inc, Austin, Tex). The main circumflex coronary artery running in the groove was cut open in its entire length, and, with the tourniquets still tight, the patency of all LV free wall branches was established with a 0.5 - $\mathrm{mm}$ soft-tip probe. These same branches were then opened with fine scissors, and their intimal surfaces were inspected for possible injuries. The tourniquets were then released, and the size of the mitral annulus was measured again.

\section{Hemodynamic Data Collection}

In 6 animals, after the placement of the subannular sutures the left circumflex coronary artery was dissected out under the LA appendage, and an ultrasonic flowmeter (Transonic T 206; Transonic Systems, Inc, Ithaca, NY) was placed on the vessel to measure coronary blood flow. The LA was cannulated through the appendage and connected to a fluid manometer. The right carotid artery of the animal was also dissected, and through this vessel a pigtail catheter (Cordis 4 F; Johnson \& Johnson, New Brunswick, NJ) was introduced into the LV cavity and connected to a physiologic pressure transducer (Spectramed P 23 XL; Spectramed). Phasic and mean arterial pressures, circumflex coronary blood flow, LV pressure, and $\mathrm{dP} / \mathrm{dt}$ were simultaneously monitored and recorded with a DASYLab (DASYTEC GmbH, Moenchengladbach, Germany) computer program. Circumflex coronary artery occlusions for 20 seconds were done in the control phase of the experiment then repeated with the subannular region plicated (tourniquets tightened). Data were collected from preocclusion baseline, then the coronary occlusion phase and the postocclusion hyperemic response were continuously recorded for analysis. Subsequently, the hearts were arrested and excised according to the same preparation and postmortem measurement protocol described previously.

\section{Data Analysis}

The size of the mitral annulus with the plicating suture tightened was compared with the annular size with the tourniquets released $(n=20)$. The numbers of branches found to be patent and occluded on probing were recorded, as were any possible intimal injuries in the location of the suture lines.

In 6 animals all recorded hemodynamic parameters and the calculated coronary vascular resistance and coronary flow reserve parameters were compared between the two phases of the experiment. All data are reported as mean \pm SEM unless otherwise stated, and statistical analyses were done with paired Student $t$ tests.

\section{Results}

Subannular suture placement was successful in all animals without coronary vessel injury or creation of hemodynamic instability. Tightening the tourniquets visibly plicated the subannular myocardium. In all cases "creases" were seen
TABLE 1. Postmortem mitral annular size measurement (n $=20)$

\begin{tabular}{lcc}
\hline & Control & Plication \\
\hline Diameter $(\mathrm{mm})$ & $30.8 \pm 0.4$ & $25.6 \pm 0.4$ \\
Circumference $(\mathrm{mm})$ & $96.8 \pm 1.1$ & $80.4 \pm 1.1$ \\
Area $\left(\mathrm{mm}^{2}\right)$ & $747 \pm 17$ & $517 \pm 14$
\end{tabular}

$\overline{\text { All values are mean } \pm \text { SEM. } P<.001 \text { for all differences between groups. }}$

TABLE 2. Hemodynamic data $(n=6)$

\begin{tabular}{|c|c|c|}
\hline & Control & Plication \\
\hline \multicolumn{3}{|l|}{ Baseline } \\
\hline $\begin{array}{l}\text { Systolic blood pressure } \\
(\mathrm{mm} \mathrm{Hg})\end{array}$ & $121 \pm 7$ & $118 \pm 8$ \\
\hline $\begin{array}{l}\text { Diastolic blood pressure } \\
\text { (mm Hg) }\end{array}$ & $87 \pm 5$ & $84 \pm 5$ \\
\hline $\begin{array}{l}\text { Mean blood pressure } \\
\text { (mm Hg) }\end{array}$ & $94 \pm 4$ & $93 \pm 6$ \\
\hline Coronary blood flow (mL/min) & $39.0 \pm 7.9$ & $37.2 \pm 7.2$ \\
\hline LA pressure $\left(\mathrm{cm} \mathrm{H}_{2} \mathrm{O}\right)$ & $6.0 \pm 0.6$ & $7.2 \pm 0.9$ \\
\hline $\mathrm{dP} / \mathrm{dt}_{\max }(\mathrm{mm} \mathrm{Hg} / \mathrm{s})^{2}$ & $1705 \pm 237$ & $1928 \pm 330$ \\
\hline $\begin{array}{l}\text { Coronary vascular resistance } \\
(\mathrm{mm} \mathrm{Hg} /[\mathrm{mL} \cdot \min ])\end{array}$ & $3.0 \pm 0.7$ & $3.1 \pm 0.7$ \\
\hline \multicolumn{3}{|l|}{ Hyperemia (maximum) } \\
\hline $\begin{array}{l}\text { Systolic blood pressure } \\
(\mathrm{mm} \mathrm{Hg})\end{array}$ & $128 \pm 8$ & $120 \pm 9$ \\
\hline $\begin{array}{l}\text { Diastolic blood pressure } \\
(\mathrm{mm} \mathrm{Hg})\end{array}$ & $84 \pm 5$ & $85 \pm 5$ \\
\hline $\begin{array}{l}\text { Mean blood pressure } \\
(\mathrm{mm} \mathrm{Hg})\end{array}$ & $96 \pm 5$ & $94 \pm 6$ \\
\hline Coronary blood flow (mL/min) & $91.8 \pm 11.7$ & $89.0 \pm 8.6$ \\
\hline $\mathrm{dP} / \mathrm{dt}_{\max }(\mathrm{mm} \mathrm{Hg} / \mathrm{s})$ & $1749 \pm 258$ & $2000 \pm 314$ \\
\hline $\begin{array}{l}\text { Coronary vascular resistance } \\
(\mathrm{mm} \mathrm{Hg} /[\mathrm{mL} \cdot \min ])\end{array}$ & $1.2 \pm 0.2$ & $1.1 \pm 0.1$ \\
\hline Flow debt (mL) & $13.0 \pm 2.6$ & $12.4 \pm 2.4$ \\
\hline Hyperemic blood flow (mL) & $65.6 \pm 27.8$ & $73.29 \pm 37.47$ \\
\hline Repayment (\%) & $444 \pm 113$ & $486 \pm 147$ \\
\hline
\end{tabular}

All values are mean \pm SEM. All differences between groups are not significant.

between the coronary branches, and the "noncompressed" subepicardial vessels could also be well identified between the pledgets (Figure 1). During the 30-minute observation period, hemodynamic instability was not seen in any animals, and we could not detect any surface color changes, irritability, or arrhythmia.

Dissection of the left main circumflex coronary artery and its branches revealed no injury related to suture placement, and among the $94 \mathrm{LV}$ free wall subepicardial branches (average 4.7 per animal), we found only 1 vessel to be compressed. In that case, coronary compression was caused by the relatively large red rubber tourniquet overhanging the pledget.

Postmortem mitral annulus data $(\mathrm{n}=20)$ are summarized in Table 1. Plication of the subannular myocardium 

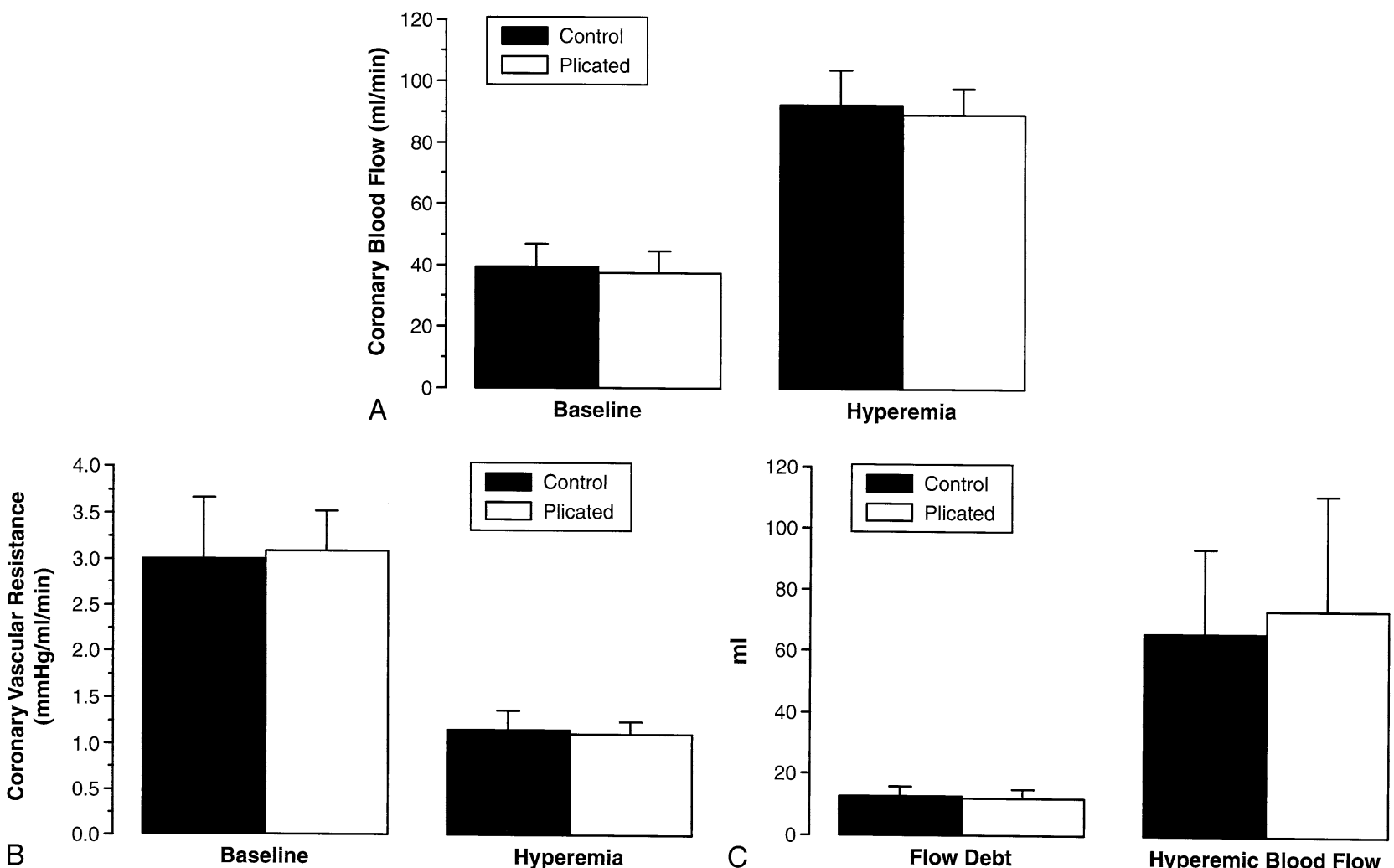

Figure 2. Circumflex coronary flow reserve parameters tested by postocclusion hyperemia test (see details of technique in text). A, Coronary blood flow. B, Coronary vascular resistance. C, Calculated blood flow reserve.

effectively reduced the mitral annular diameter and circumference by $17 \%$ and reduced the mitral annular area by $31 \%$.

Hemodynamic parameters at baseline and during maximum hyperemia and calculated coronary vascular resistance and coronary flow reserve parameters $(\mathrm{n}=6)$ are reported in Table 2. Between the two phases of the experiment, no significant changes were seen in systolic, diastolic, or mean blood pressure, LV pressure, LV systolic function $\left(\mathrm{dP} / \mathrm{dt}_{\max }\right)$, or LA pressure. Subannular myocardial plication had no significant effect on circumflex coronary blood flow or coronary vascular resistance, and coronary flow reserve tested by reactive hyperemic response also remained unchanged (Figure 2).

\section{Discussion}

Morphologically, the mitral annulus can be divided into two parts, a shorter anterior section and a longer posterior section. ${ }^{1}$ The anterior annulus is formed by strong fibroelastic tissue and includes the left and right fibrous trigones and the strong aorticomitral membrane between the two. This part of the annulus belongs to the fibrous skeleton of the heart, and it does not show any shape or size changes during cardiac contractions. On the other hand, the posterior or mural annulus does not have well-defined fibroelastic ele- ments. It is directly attached to the LV myocardium, and as the muscle moves, the mural annulus moves with it throughout the cardiac cycle. During diastole, the annulus is pulled outward by the relaxing posterior ventricular wall, and the diastolic orifice enlarges and becomes more circular in shape, facilitating ventricular filling. ${ }^{1,2}$ Systolic contraction of the spirally positioned ventricular muscle fibers bends the posterior annulus toward the relatively immobile fibroelastic part, and during ventricular ejection the annulus becomes smaller and its shape more oval, contributing to valvular competence. ${ }^{1,2}$ The preservation of this annular flexibility during surgical procedures is considered beneficial. ${ }^{10,12,19,20}$

It is widely believed that under pathologic circumstances the posterior annulus dilates, because it is only supported by muscle, whereas the strong fibrous anterior annulus remains essentially unchanged. ${ }^{1,2}$ Although this fundamental anatomic pathologic principle has been challenged recent$1 y,{ }^{21,22}$ to date all annular "remodeling" procedures have been designed to target and downsize the posterior (mural) annulus in particular. ${ }^{8-17}$

It is not debated, however, that the close relationship in between the posterior LV wall and mural annulus results in mitral annular dilatation whenever LV enlargement develops. $^{4-7}$ With the exception of rheumatic mitral valve dis- 
ease, when fibrosis or calcification might prevent excessive annular dilatation, ${ }^{3}$ progressive $\mathrm{LV}$ chamber enlargement is almost always associated with a dilated annulus. ${ }^{3-7}$ It is seen in most forms of cardiomyopathy, but by itself cannot be blamed for the development of valvular incompetence. ${ }^{4-7}$ If the rest of the mitral apparatus remains intact, the 1.5 to 2 times larger combined surface area of the valve leaflets is able to compensate for this dilatation, closing off the enlarged annular area. ${ }^{1}$ The primary cause of functional mitral regurgitation in various forms of cardiomyopathy is the ventricle becoming more spherical. As a result, the papillary muscles "migrate" laterally, pulling leaflet edges apart. ${ }^{4-7}$ As dilatation continues, however, mitral annular dilatation follows as a rule, ${ }^{4,6,7}$ and it becomes a significant contributing factor in valvular incompetence.

The importance of these facts was emphasized by Bolling, ${ }^{18}$ who started to treat functional mitral regurgitation in patients with cardiomyopathy by "undersizing" the mitral orifice. The technique does not directly address LV spherical remodeling, but by "offloading" the LV, it results in a significant volume reduction and good longer term clinical results. ${ }^{18,23}$

A most recent experimental method by Timek and coworkers, ${ }^{24,25}$ septolateral cinching, addresses mitral annular dilatation. The procedure consists of a single suture placement across the mitral orifice between the midseptal annulus and the midlateral annulus, and by suture tightening the midlateral annulus is pulled closer to the septal annulus. In normal sheep hearts, the annular area was significantly downsized, ${ }^{24}$ and in an acute ischemic animal model the development of mitral regurgitation could also be abolished. ${ }^{25}$ This method preserves the dynamic nature of the mitral annulus; however, suture placement still requires opening of the LA and cardiopulmonary bypass.

The idea of reducing mitral annular size with an external suture technique is not new. In the mid 1950s Davila and Glover $^{26,27}$ developed a method to encircle the mitral orifice on the beating heart with a 0.25 -inch cotton umbilical tape. Their purse-string suture was placed directly into the atrioventricular groove posteriorly and required blunt dissection underneath the left circumflex coronary artery and its branches and also beneath the coronary sinus (because of suture size, intramyocardial placement was considered damaging). To properly position the tape around the anterior and septal parts of the annulus, special maneuvers were also needed, but with this circumferential suture a significant annular size reduction was clearly achieved. This technique, however, resulted in frequent coronary artery occlusions or arrhythmia believed to be caused by ischemia. Tape erosions into the LA also frequently occurred. In their cumulative series of 58 patients, a $58 \%$ in-hospital mortality was reported, ${ }^{27}$ and not surprisingly the safer open mitral valve replacement and open annuloplasty techniques gained popularity after the advent of cardiopulmonary bypass.

Since those original reports, some veterinary surgeons have continued to use this purse-string technique to treat dilating cardiomyopathy in dogs because it is an off-bypass method. ${ }^{28}$ Through the years, technical modifications have been made and finer and more tissue friendly suture material (polyester suture with silicone elastomer tubing coverage) have been used, but the overall results are still quite poor as a result of coronary vessel occlusion, coronary sinus laceration, or erosion into the LA. ${ }^{28,29}$

Our technique is also an external plication, and the sutures are placed on the beating heart without cardiopulmonary bypass. As opposed to the previously described method, however, we place the Prolene sutures directly into the subannular myocardium, well away from the atrioventricular groove. Surgical dissection around coronary sinus and the main circumflex coronary artery is avoided, and compression or laceration of these vessels is not a concern. The partial circumferential suture dives deep under subepicardial LV free wall coronary branches, and multiple pledgets prevent the suture from cutting into the myocardium. Mitral annuloreduction with our method may be modest relative to that provided by open techniques, but it was achieved through a safe off-bypass method, without compromising circumflex coronary blood flow. Our procedure also follows the principles of posterior annuloplasty (the posterior LV free wall segment corresponds to mural leaflet attachment).

Most recently, Liel-Cohen and coworkers ${ }^{30}$ published an infarct plication method to eliminate ischemic mitral regurgitation. In a sheep model, posterior wall infarction was created by coronary artery ligation, and echocardiography was used to evaluate the mitral apparatus as LV dilatation and moderate mitral regurgitation developed. Direct surgical plication of the infarcted area 8 weeks later practically eliminated mitral regurgitation. The procedure significantly reduced interpapillary muscle distance and leaflet tethering distances but had no effect on the already dilated mitral orifice. These benefits occurred with no changes in overall LV performance and with only mild decreases in total LV volumes, indicating the importance of infarct-related localized papillary muscle lateral migration and its significance relative to annular dilatation in general.

In the referenced experiments, plication was done on an infarcted and aneurysmally dilated localized area without worrying about residual blood supply. With a similar plicating concept in mind, we placed our sutures into living and functioning myocardium, and compression of subepicardial branches and coronary blood flow to the entire LV free wall were therefore our major concern. Working with healthy hearts, we were unable to prove elimination of mitral regurgitation per se, but the 
lack of alterations in LV systolic function, baseline coronary blood flow, and particularly coronary flow reserve after plication indicate good preservation of myocardial tissue viability and performance.

\section{Limitations of the Study}

These experiments were done on nondilated, healthy hearts, and presumably none of the animals had mitral regurgitation. Because of the lack of echocardiographic equipment, no in vivo measurements were done. The sizing on the mitral annulus was done post mortem in every case, and the annular geometry measured with circular shape valve sizers after the animal was killed does not represent that seen in in vivo circumstances. From our data it cannot be assumed that this indirect annuloreduction will be able to abolish severe functional mitral regurgitation in cardiomyopathy. It may, however, prevent the progression of annular dilatation along LV free wall.

Our surgical method is empirical at this point, and we are unable to offer an exact quantitative measure of how much plication is safe. It should also be emphasized that the healthy canine myocardium has excellent collateral circulation, and therefore any possible localized or subendocardial ischemia created by the suture line itself may have remained undetected, although the unchanged coronary flow reserve is good evidence against it. To support our hypothesis, prolonged experiments with long-term surviving animals and detailed histopathologic studies are needed.

We are thankful for Mr Kázmér Deák for artistic illustration.

\section{References}

1. van Rijk-Zwikker GL, Delemarre BJ, Huysmans HA. Mitral valve anatomy and morphology: relevance to mitral valve replacement and valve reconstruction. J Card Surg. 1994;9(2 Suppl):255-61.

2. Ormiston JA, Shah PM, Tei C, Wong M. Size and motion of the mitral valve annulus in man. I. A two-dimensional echocardiographic method and findings in normal subjects. Circulation. 1981;64:113-20.

3. Roberts WC. Morphologic features of the normal and abnormal mitral valve. Am J Cardiol. 1983;51:1005-28.

4. Chandraratna PA, Aronow WS. Mitral valve ring in normal vs dilated left ventricle. Cross-sectional echocardiographic study. Chest. 1981; 79:51-4.

5. Kono T, Sabbah HN, Stein PD, Brymer JF, Khaja F. Left ventricular shape as a determinant of functional mitral regurgitation in patients with severe heart failure secondary to either coronary artery disease or idiopathic dilated cardiomyopathy. Am J Cardiol. 1991;68:355-9.

6. Timek TA, Dagum P, Lai DT, Liang D, Daughters GT, Ingels NB Jr, et al. Pathogenesis of mitral regurgitation in tachycardia-induced cardiomyopathy. Circulation. 2001;104(Suppl 1):I47-53.

7. Kono T, Sabbah HN, Rosman H, Alam M, Jafri S, Goldstein S. Left ventricular shape is the primary determinant of functional mitral regurgitation in heart failure. J Am Coll Cardiol. 1992;20:594-8.

8. Frater RM. Posterior mitral annuloplasty. J Heart Valve Dis. 1993;2: 629.

9. Carpentier A, Deloche A, Dauptain J, Soyer R, Blondeau P, Piwnica A, et al. A new reconstructive operation for correction of mitral and tricuspid insufficiency. J Thorac Cardiovasc Surg. 1971;61:1-13.
10. Duran CG, Ubago JL. Clinical and hemodynamic performance of a totally flexible prosthetic ring for atrioventricular valve reconstruction. Ann Thorac Surg. 1976;22:458-63.

11. Reece IJ, Cooley DA, Painvin GA, Okereke OU, Powers PL, Pechacek LW, et al. Surgical treatment of mitral systolic click syndrome: results in 37 patients. Ann Thorac Surg. 1985;39:155-8.

12. Cosgrove DM 3rd, Arcidi JM, Rodriguez L, Stewart WJ, Powell K, Thomas JD. Initial experience with the Cosgrove-Edwards Annuloplasty System. Ann Thorac Surg. 1995;60:499-503.

13. Burr LH, Krayenbuhl C, Sutton MS, Paneth M. The mitral plication suture: a new technique of mitral valve repair. $J$ Thorac Cardiovasc Surg. 1977;73:589-95.

14. Ricchi A, Ortu P, Cirio EM, Falchi S, Lixi G, Martelli V. Linear segmental annuloplasty for mitral valve repair. Ann Thorac Surg. 1997;63:1805-6.

15. Nagy ZL, Bodi A, Vaszily M, Szerafin T, Horvath A, Peterffy A. Five-year experience with a suture annuloplasty for mitral valve repair. Scand Cardiovasc J. 2000;34:528-32.

16. Pellegrini A, Quaini E, Colombo T, Lanfranchi M, Russo C, Vitali E. Posterior annuloplasty in the surgical treatment of mitral insufficiency. J Heart Valve Dis. 1993;2:633-8.

17. Salati M, Scrofani R, Santoli C. Annular remodelling with pericardial reinforcement: surgical technique and early results. J Heart Valve Dis. 1993;2:639-41.

18. Bolling SF. Mitral reconstruction in cardiomyopathy. J Heart Valve Dis. 2002;11(Suppl 1):S26-31.

19. David TE, Komeda M, Pollick C, Burns RJ. Mitral valve annuloplasty: the effect of the type on left ventricular function. Ann Thorac Surg. 1989;47:524-7.

20. Dagum P, Timek T, Green GR, Daughters GT, Liang D, Ingels NB, et al. Three dimensional geometric comparison of partial and complete flexible mitral annuloplasty rings. J Thorac Cardiovasc Surg. 2001; 122:665-73.

21. Hueb AC, Jatene FB, Moreira LF, Pomerantzeff PM, Kallas E, de Oliveira SA. Ventricular remodeling and mitral valve modifications in dilated cardiomyopathy: new insights from anatomic study. $J$ Thorac Cardiovasc Surg. 2002;124:1216-24.

22. McCarthy PM. Does the intertrigonal distance dilate? Never say never. J Thorac Cardiovasc Surg. 2002;124:1078-9.

23. Radovanovic N, Mihajlovic B, Selestiansky J, Torbica V, Mijatov M, Popov M, et al. Reductive annuloplasty of double orifices in patients with primary dilated cardiomyopathy. Ann Thorac Surg. 2002;73: 751-5.

24. Timek TA, Lai DT, Tibayan FA, Daughters GT, Liang D, Dagum P, et al. Septal-lateral annular cinching (SLAC) reduces mitral annular size without perturbing normal annular dynamics. J Heart Valve Dis. 2002;11:2-9.

25. Timek TA, Lai DT, Tibayan F, Liang D, Daughters GT, Dagum P, et al. Septal-lateral annular cinching abolishes acute ischemic mitral regurgitation. J Thorac Cardiovasc Surg. 2002;123:881-8.

26. Davila JC, Mattson WW, O'Neill TJ, Glover RP. A method for the surgical correction of mitral insufficiency. I. Preliminary considerations. Surg Gynecol Obstet. 1954;98:407-12.

27. Davila JC, Glover RP. Circumferential suture of the mitral valve for the correction of regurgitation. Am J Cardiol. 1958;2:267-75.

28. Buchanan JW, Sammarco CD. Circumferential suture of the mitral annulus for correction of mitral regurgitation in dogs. Vet Surg. 1998; 27:182-93.

29. Kerstetter KK, Sackman JE, Buchanan JW, Bright JM, Krahwinkel DJ, Bright RM, et al. Short-term hemodynamic evaluation of circumferential mitral annuloplasty for correction of mitral valve regurgitation in dogs. Vet Surg. 1998;27:216-23.

30. Liel-Cohen N, Guerrero JL, Otsuji Y, Handschumacher MD, Rudski LG, Hunziker PR, et al. Design of a new surgical approach for ventricular remodeling to relieve ischemic mitral regurgitation: insights from 3-dimensional echocardiography. Circulation. 2000;101: 2756-63. 